\title{
Optical Ligand to Ligand Charge Transfer of Metal Complexes Including Ligand-Based Mixed-Valence Systems
}

\author{
ARND VOGLER and HORST KUNKE,LY \\ Institut für Anorganische Chemie. \\ Universität Regensturg, \\ Universitätsstr. 31 . \\ D.8400 Regenstiurg. \\ Federal Republic of Germany
}

\begin{abstract}
The electronic spectra of metal complexes which contain a reducing and an oxidizing ligand $\left(L_{\text {red }}-M-L_{o x}\right.$ ) are characterized by ligand to ligand charge transfer (LLCT) absorptions. A specific form of $L_{\text {red }}-M-L_{\text {ox }}$ complexes are ligand-based mixedvalence (LBMV) compounds which contain the same ligand in two different redox states. In this case the ligand-ligand interaction may lead to a partial or even complete electronic delocalization between the reduced and oxidized form of the ligands. As a consequence, the "LLCT" transition loses its CT character sinise it takes place between delocalized orbitals.
\end{abstract}

Key Words: mixed-valence complexes, electronic spectra, optical electron transfer

\section{INTRODUCTION}

The discussion of the electronic interaction in coordination compounds is frequently restricted to the coupling between the central metal and the ligands. However, the metal also facilitates the rnutual interaction of the ligands. A special and very interesting case of this interaction occurs if a complex contains simultaneously an

Comments Inorg. Chem.

1990. Vol. 9. No. 3 \& 4. pp. 201-220

Reprints available directly from the publisher

Photocopying permitted by license only c 1990 Gordon and Breach. Science Publishers. Inc. Printed in Great Britain 
electron donor (or reducing) ligand $\mathrm{L}_{\mathrm{red}}$ and an acceptor (or oxidizing) ligand $L_{\text {ox }}$. In the electronic spectra of such complexes $L_{\text {red }}-$ $\mathrm{M}-\mathrm{L}_{\text {ox }}$ an absorption band may appear which belongs to a charge transfer (CT) transition from the donor to the acceptor ligand. Ligand to ligand charge transfer (LLCT) is a rather new type of optical electronic transition which has been studied only recently but is now gaining increasing attention.

Before a detailed description of LLCT is presented it is appropriate to mention briefly the classical electronic CT transitions of metal complexes. CT transitions are classified according to the redox sites. ${ }^{2}$

Ligand to metal CT (LMCT) absorption bands are observed at low energies if the metal is oxidizing and the ligand reducing. $\mathrm{Co}(\mathrm{III})$ and $\mathrm{Fe}$ (III) complexes are well-documented examples. The colors of $\mathrm{d}^{0}$ oxometallates such as the yellow $\mathrm{CrO}_{4}^{2-}$ and the violet $\mathrm{MnO}_{4}^{-}$are caused by LMCT bands.

Metal to ligand CT (MLCT) is another classical optical transition of metal complexes. MLCT absorptions appear at long wavelengths if the metal is reducing and a ligand provides low-energy empty orbitals. Complexes such as $\left[\mathrm{Fe}(\mathrm{CN})_{6}\right]^{4-}$ and $\left[\mathrm{Ru}(\text { bipy })_{3}\right]^{2+}$ (bipy $=2.2^{\prime}$-bipyridyl) are typical cases. In addition, organometallics which contain a metal in a low oxidation state and $\pi$-accepting ligands such as an olefin or an aromatic molecule are characterized by low-energy MLCT bands. ${ }^{1.2}$

Metal to metal CT (MMCT) bands occur only in the absorption spectra of binuclear (or polynuclear) complexes which contain a reducing and an oxidizing metal. ${ }^{1}$ Two cases can be distinguished. Both metals are either bridged by a suitable ligand $\left(\mathrm{M}_{\mathrm{red}}-\mathrm{L}-\mathrm{M}_{\mathrm{ox}}\right)^{1.3}$ or connected by a direct but polar metal-metal bond $\left(\mathrm{M}_{\text {red }}-\mathrm{M}_{\mathrm{ox}}\right)^{4-6}$ The binuclear complexes $\left[\left(\mathrm{NH}_{3}\right)_{5} \mathrm{Co}^{\mathrm{III}} \mathrm{NCRu}{ }^{\mathrm{II}}(\mathrm{CN})_{5}\right]^{-1.3}$ and $\left[\mathrm{Ph}_{3} \mathrm{PAu}^{\mathrm{I}}-\mathrm{Co}^{-1}(\mathrm{CO})_{4}\right]^{4}$ are typical compounds which display lowenergy MMCT absorption bands.

The following discussion of LLCT is presented in four parts. First, LLCT is shown to be a very general phenomenon which can take place in all mixed-ligand complexes provided they contain a reducing and an oxidizing ligand of any type. Secondly, ligandbased (LB) mixed-valence (MV) complexes are discussed. The third part deals with excited state processes involving LLCT states. Finally, two special cases of LLCT, namely intraligand CT (ILCT) and outer-sphere LLCT. are described. 


\section{LLCT OF MIXED-LIGAND COMPLEXES}

Any complex of the type $\mathrm{L}_{\text {red }}-\mathrm{M}-\mathrm{L}_{\text {ox }}$ may display a LLCT band in its absorption spectrum. In principle, such a CT band should also be observed if the donor and acceptor ligands interact without an intervening metal. Pyridinium halides and related ion pairs can be taken as examples:

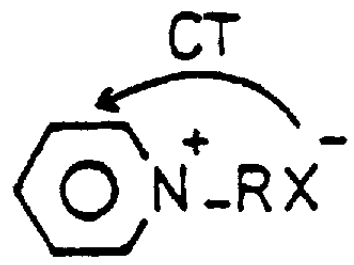

It is well known that the spectra of these compounds show lowenergy absorptions which belong to outer-sphere (halide to fyridinium) CT transitions. ${ }^{7}$ It is then by no means surprising that such CT transitions also occur if a metal mediates an inner-sphere interaction between the same donor and acceptor:

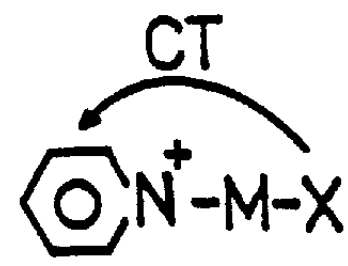

However, in many cases LLCT bands are difficult to detect since they may be hidden under or obscured by absorption of different origin. An unambiguous assignment of LLCT bands is facilitated if other absorptions do not occur in the same wavelength region. In some cases a clear identification of LLCT bands is possible if they occur at very long wavelengths where the appearance of these absorptions is unique. This requires a rather strong reducing and oxidizing strength of both ligands. In other cases LLCT bands rnay occur at much higher energies. It is then certainly an advantage if the metal is rather redox inert and any interierence by long-wavelength LMCT and MLCT absorptions can be excluded. Metals such as $\mathrm{Zn}$ (II), $\mathrm{Cd}$ (II) or $\mathrm{Rh}$ (III) should serve this purpose. Another useful criterion for the detection of LLCT bands is the independence of their energy of the type of metal unless the inter- 
action of the metal with ligands of interest exerts a large influence on its electronic structure.

LLCT bands appear in the absorption spectra of complexes which contain the following donor and acceptor ligands: Donor: $\mathrm{X}^{-}$(halide), $\mathrm{RS}^{-}$(thiolate), $\mathrm{R}^{-}(\mathrm{R}=$ alkyl and aryl groups). Acceptor: bipy, o-phen (o-phenanthroline), porphyrins.

Historically, the first LLCT assignment was made by Coates and Green in $1962 .{ }^{8}$ They concluded that the long-wavelength absorptions of $\left[\mathrm{Be}^{\mathrm{Il}}\right.$ (bipy) $\left.\mathrm{X}_{2}\right]$ and $\left[\mathrm{Be}^{\mathrm{II}}\right.$ (bipy) $\left.\mathrm{R}_{2}\right]$ are caused by an optical electron transfer from $X^{-}$or $R^{-}$to bipy. $\mathrm{Be}(\mathrm{II})$ as a redox inert closed shell metal certainly does not participate in low-energy electronic transitions. The LLCT bands are red-shifted in the order of increasing reducing strength of the halide: $\lambda_{\max }=352 \mathrm{~nm}\left(\mathrm{Cl}^{-}\right)$, $364 \mathrm{~nm}\left(\mathrm{Br}^{-}\right) .368 \mathrm{~nm}\left(\mathrm{I}^{-}\right)$. Upon substitution of the halide by carbanions the LLCT bands appear at $\lambda=353 \mathrm{~nm}\left(\mathrm{C}_{6} \mathrm{H}_{5}^{-}\right), 395$ $\mathrm{nm}\left(\mathrm{CH}_{3}^{-}\right)$, and $461 \mathrm{~nm}\left(\mathrm{C}_{2} \mathrm{H}_{-}^{-}\right)$. The absorption spectrum of $\left[\mathrm{Tl}(\text { bipy })_{2} \mathrm{l}_{2}\right]^{+}$shows a LLCT (1- to bipy) band at $\lambda_{\max }=374 \mathrm{~nm} .^{9}$ The complexes $\left[\mathrm{Zn}(\right.$ bipy $\left.) \mathrm{R}_{2}\right]$ are also characterized by low-energy LLCT bands at $\lambda_{\max }=360 \mathrm{~nm}\left(\mathrm{CH}_{5}^{-}\right) .^{10.11} 420 \mathrm{~nm}\left(\mathrm{C}_{2} \mathrm{H}_{5}^{-}\right) .{ }^{11.12}$ $426 \mathrm{~nm}\left(\mathrm{C}_{3} \mathrm{H}_{7}^{-}\right),{ }^{10}$ and $430 \mathrm{~nm}\left(\mathrm{C}_{4} \mathrm{H}_{9}^{-}\right),{ }^{10} \mathrm{Zn}(\mathrm{II})$ as a redox inert $\mathrm{d}^{10}$ metal certainly does not take part in any low-energy transition.

Alkyl and arylthiolates are well suited as donor ligands. too. So it is not surprising that complexes of the type $\mathrm{Zn}(0-p h e n)(\mathrm{SR})_{2}$ and $\mathrm{Cd}(\mathrm{o}$-phen $)(\mathrm{SR})_{2}$ with $\mathrm{R}=$ aryl display LLCT bands in their absorption spectra. ${ }^{13.14}$ These bands appear in the near UV.

LLCT bands are also expected to occur for the square-planar $\mathrm{d}^{8}$ complexes $\left[\mathrm{Pt}(\right.$ bipy $\left.) \mathrm{X}_{2}\right]$. However, the electronic spectra are certainly more complicated due to the presence of bands of different origin. The long-wavelength bands of $\left[\mathrm{Pt}(\right.$ bipy $\left.) \mathrm{X}_{2}\right]$ which undergo a considerable red shift in the series $\mathrm{X}=\mathrm{Cl}$. Br and I were assigned to MLCT transitions. ${ }^{15}$ This red shift could be caused by a progressive destabilization of the filled $\mathrm{d}_{\pi}$-orbitals by $\pi$-donor interaction with the halide ligands. At the same time the resulting MO's gain an increasing contribution from the halide. Consequently. these MLCT transitions have an increasing LLCT character from $\mathrm{X}=\mathrm{Cl}$ to $\mathrm{I}$. Complexes of the type $\left[\mathrm{Pt}\left(\right.\right.$ bipy $\left.\left.^{\prime}\right) \mathrm{R}_{2}\right]$ also display long-wavelength $C T$ bands (e.g., $\lambda_{\max } \sim 500 \mathrm{~nm}$ for $\mathrm{R}=$ $\left.\mathrm{C}_{2} \mathrm{H}_{5}\right){ }^{16}$ These bands show a strong negative solvatochromism. Since $\pi$ orbitals of the alkyl anion ligands are not available these 
bands should be assigned to LLCT transitions from the $\sigma$-boriding electron pair of the $\mathrm{R}^{-}$ligand to bipy. A MLCT assignment can be excluded since the complex [Pt(bipy) (ethylenediamine) $]^{2+}$ does not exhibit such a long-wavelength band. ${ }^{17}$ The ethylenediamine is also a $\sigma$ donor ligand but much less reducing than $\mathbf{R}^{-}$.

The absorption spectrum of carboxycytochrome $P 450$ is quite unusual. This compound is an octahedral $\mathrm{Fe}(\mathrm{II})$ complex which contains a porphyrin ligand. Axial ligands are $\mathrm{CO}$ and $\mathrm{RS}^{-}$. This metalloporphyrin shows the Soret band $\left(S_{0} \rightarrow S_{2} \pi \pi^{*}\right.$ intraligand transition of the porphyrin) at extremely long wavelength $(450 \mathrm{~nm})$ and an additional intense band in the near UV $(360 \mathrm{~nm})$. The latter band was assigned to a LLCT transition from the axial S-R- ligand to the $\pi^{*}$ orbitals of the porphyrin. ${ }^{18}$ It was recently proven that this assignment is indeed correct. The absorption spectrum of $\mathrm{Zn}$ (II) porphyrin thiolate complexes is very similar to that of $P 450$ including the LLCT band. ${ }^{19.20}$ Any electronic transition involving $\mathrm{Zn}$ (II) cannot occur in this energy region.

There are certainly many other complexes which are expested to show LLCT bands in their electronic spectra. Quite often such LLCT bands could be obscured by other absorptions and only a careful analysis of the spectrum may lead to their detection. Sometimes the spectra have simply not been recorded although LLCT bands are anticipated to appear at long wavelengths. For example, calculations have shown that the HOMO of the carbyne complex $\mathrm{Cr}(\mathrm{CO})_{4}(\mathrm{C}-\mathrm{Ph}) \mathrm{Br}$ is located at the bromide ligand while the LUMO is derived from the carbyne. ${ }^{21}$ Consequently, a low-energy LI.CT band should occur but the spectrum of this complex is yet unknown.

\section{LIGAND-BASED MIXED-VALENCE (LBMV) COMPLEXES}

Ligand-based mixed-valence complexes contain the same ligand in a reduced and oxidized form. LLCT absorptions should then appear in the electronic spectra of these compounds. However, the electronic coupling of both ligands introduces a serious complication. A strong coupling may lead to a complete electronic delocalization between both ligands. The reduced and oxidized form 
of the ligands then yield two identical ligands in an intermediate redox state. A "LLCT" band could still occur but the electronic transition does not have any CT contribution but involves delocalized orbitals.

LBMV complexes are quite analogous to metal-based (MB) MV complexes. Since the theory of MBMV complexes is well developed, ${ }^{22-28}$ some fundamental features of this theory are discussed first to facilitate the description of LBMV compounds. Bi- or polynuclear complexes which contain the same metal in two different oxidation states are MBMV compounds. Generally, the reducing and oxidizing metal are bridged by a suitable ligand $\left(\mathrm{M}_{\mathrm{red}}-\mathrm{L}-\right.$ $\left.M_{o x}\right)$. The best known examples are those compounds which contain ruthenium in the oxidation states $\mathrm{Il}$ and III $\left(\mathrm{Ru}^{\mathrm{II}}-\mathrm{L}-\mathrm{Ru}^{\mathrm{III}}\right)$. Since both metals are electronically coupled an electron delocalization takes place. With increasing metal-metal interaction the individual metal ions $\mathrm{Ru}^{\mathrm{II}}$ and $\mathrm{Ru}^{\mathrm{III}}$ lose their identity. Finally, the valence orbitals of both metals are completely delocalized and the metals no longer exist in well-defined ("trapped") oxidation states. Both ruthenium atoms now have the intermediate oxidation state 2.5.

For a delocalized MV complex $L_{n} R u^{2.5}-L_{B}-R u^{2.5} L_{n}^{\prime}\left(L=L^{\prime}\right)$ a redox asymmetry can be introduced by chemical modification If $L$ and $L^{\prime}$ are different ligands which stabilize $R u^{I I}$ and $R u^{I I I}$ to a different extent, the resonance formula $L_{n} R u^{\mathrm{II}}-\mathrm{L}_{\mathrm{B}}-\mathrm{Ru}^{\mathrm{II}} \mathrm{L}_{n}^{\prime}$ may contribute more to the real electron distribution in the complex. However, the influence of the ligands on the redox asymmetry is usually small compared to the variation of the metal. A substitution of one $\mathrm{Ru}$ by the homologous $\mathrm{Fe}$ reduces the delocalization greatly due to the different energies of the valence orbitals of both metals. In a more general sense such binuclear mixed-metal complexes with a reducing and an oxidizing metal can still be viewed as $M V$ compounds. ${ }^{3,29}$

The extent of delocalization can be determined or estimated by experimental data. ${ }^{22-28}$ In favorable cases structural features allow a distinction since bond lengths and angles will depend on the oxidation state. An important feature is the MMCT absorption band. With increasing delocalization this band still appears but loses its CT character. As a consequence the energy of this band no longer depends on the polarity of the solvent.

The ideas developed above will now be applied to LBMV com- 
plexes. First, some interesting complexes with unknown optical properties are described (a). Secondly, LBMV compounds are discussed which are characterized by a LLCT absorption (b). However, the extent of CT contribution to this LLCT transition is not clear. Then complexes will be presented which contain completely delocalized MV ligands (c). The "LLCT"bands do not have any CT character. The final section deals with LBMV complexes which are definitely redox asymmetric and their LLCT transitions have a real CT contribution (d).

(a) Let us first consider the CT interaction in a purely organic system which may also be used for a LBMV complex. A suilable redox-active compound is p-quinone which can be reversibly reduced to the semiquinone radical anion and the deprotonated hydroquinone dianion by two consecutive one-electron transfer processes:<smiles>C=CC1([O-])C=CC(=CC=CC2=CC([Hg])C=CC2[O])C=C1</smiles>

In 1844 Wöhler observed that a mixture of the quinone and hydroquinone yields the dark-colored quinhydrone. ${ }^{30}$ The color is caused by an intense absorption which involves a $C T$ transition from the reducing hydroquinone to the oxidizing quinone. In solution this color disappears since the quinhydrone dissociates into its components. Staab and Rebafka avoided this dissociation by the incorporation of the quinone and hydroquinone $n$ a paracyclophan ${ }^{31}$ :

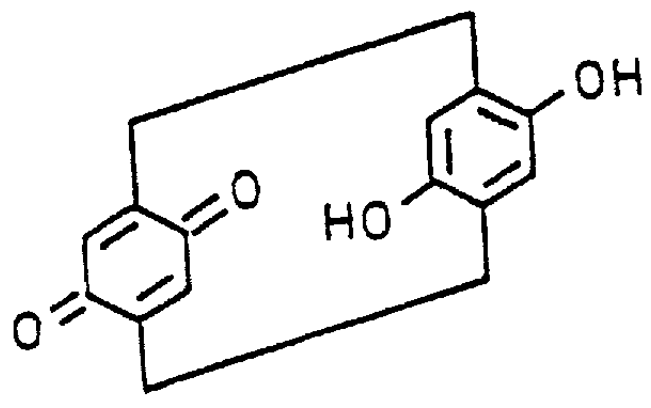


The resulting compound is blue-colored due to the hydroquinone to quinone CT absorption. It should now also be possible to mediate the $C T$ interaction between quinone and hydroquinone by an intervening metal atom yielding the prototype of a LBMV complex. When $\mathrm{Ni}(\mathrm{CO})_{4}$ reacts with duroquinone a sandwich complex is formed in which two quinone molecules are coordinated as diolefin ${ }^{32}$ :

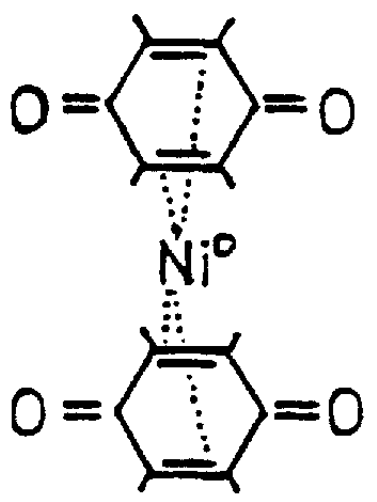

A LBMV complex is thus apparently not formed. However, when stronger oxidizing quinones react with $\mathrm{Ni}(\mathrm{CO})_{4}$ a dark-colored material is formed ${ }^{32}$ which may indeed be the desired LBMV compound:

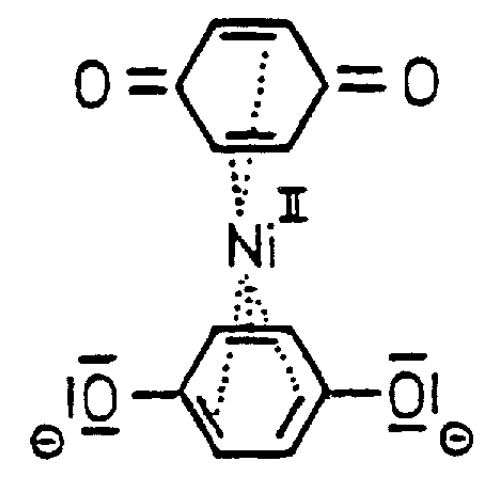

Due to the insolubility of this material any further characterization which could confirm such a structure was not achieved. It would be most interesting to know if this compound really contains a quinone and a hydroquinone dianion ("trapped valencies") or two coupled semiquinone ligands ("intermediate valency" or delocal. ized ligands). 
A similar organometallic LBMV compound may be a cobalt(I) complex which seems to contain tetraphenylcyclopentadienone (tetracyclone) and its dianion as MV ligands ${ }^{33}$ :

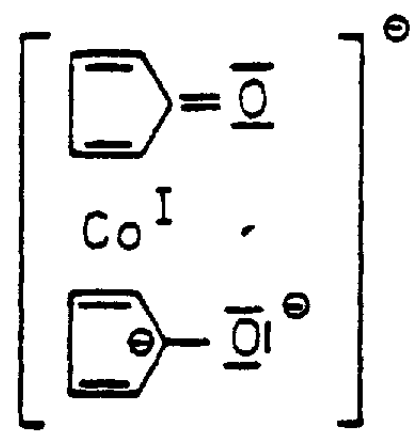

This complex anion can be protonated to yield a stable neutral compound. There is evidence that the proton bridges the oxygen atom of both ligands. Interestingly, this compound crystallizes in two modifications of different color. Unfortunately, the extent of electronic coupling and delocalization of both ligands is not known.

Instead of p-quinone and its reduced forms, the ortho isomers o-quinone, o-semiquinone and catecholate can be used as ligands. Chelates which are coordinated via both oxygen atoms are formed. Numerous complexes of this type have been synthesized. ${ }^{34,35}$ In some cases it was established by X-ray crystallography that LEMMV complexes with trapped valencies do indeed exist. The six-coordinate complex $\left[\mathrm{MO}^{\vee}(9,10 \text {-phenanthrencatecholate })_{2}(9,10\right.$-phenanthrensemiquinone)] is an example of a real LBMV complex which contains a ligand in two different redox states. ${ }^{34.36}$ This is also true for the cation [Co(II)(o-benzoquinonediimid) ${ }_{2}$ (o-benzosemiquinonediimide) $]^{+} .{ }^{37}$ The oxygen atoms of 0 -quinone and its reduced form are substituted by NH. The complex is five-coordinate. The two quinonediimide ligands are chelating while: the semiquinonediimide acts as monodentate ligand. Further examples are described by Pierpont and Buchanan. ${ }^{3+}$ Unfortunately, LlCCT bands were not detected for these complexes. The extent of electronic coupling of the MV ligands is also not clear.

(b) In this section LBMV complexes are described which display a LLCT band in their electronic spectra. However, the extert of CT contribution to the "LLCT" transitions is now known in these cases. In the following discussion the term LLCT is replaced by 
intervalence transfer (IT) if the MV ligands are delocalized or the CT character of the "LLCT" bands has not been determined or estimated experimentally.

Buchanan and Pierpont were the first who assigned a near-IR absorption $\left(\lambda_{\max } \sim 1300 \mathrm{~nm}\right)$ of $\left[\mathrm{Co}^{11 I}(3,5\right.$-di-tert.-butylcatecholate)(3.5-di-tert.-butylsemiquinone)(bipy)] to a ligand-based IT transition..$^{34.38}$ Since the complex contains MV ligands with trapped valencies, as indicated by the X-ray structure, the IT band should belong to a real LLCT (catecholate to semiquinone) transition, but this remains to be confirmed. A similar system was studied by Hendrickson and his group. The complex [ $\mathrm{Fe}^{\mathrm{Ill}}(9,10$-phenanthrencatecholate)(9,10-phenanthrene semiquinone)(bipy)] and related compounds display an IT band near $1100 \mathrm{~nm} .{ }^{39}$ In polar solutions this absorption disappears due to the change of redox states.

Many complexes of the general formula $\left[\mathrm{M}(\mathrm{N}-\mathrm{N})_{3}\right]^{-}$, with $\mathrm{N}-$ $\mathrm{N}=$ bipy and other polypyridyl ligands, can be reduced, often in several consecutive steps. ${ }^{40}$ When the reduction occurs at the $\mathrm{N}-$ $\mathrm{N}$ ligands LBMV complexes of the type $\left[\mathrm{M}(\mathrm{N}-\mathrm{N})_{2}\left(\mathrm{~N}-\mathrm{N}^{-}\right)\right]^{\mathrm{n}-1}$ or $\left[\mathrm{M}(\mathrm{N}-\mathrm{N})\left(\mathrm{N}-\mathrm{N}^{-}\right)_{2}\right]^{n-2}$ are formed. The complexes $\left[\mathrm{Ru}^{\mathrm{II}} \text { (bipy) }{ }_{2}\left(\text { bipy }^{-}\right)\right]^{+},\left[\mathrm{Ru}^{\mathrm{II}} \text { (bipy) }\left(\text { bipy }^{-}\right)_{2}\right]^{0},\left[\mathrm{Ir}^{\mathrm{III}} \text { (bipy) }\right)_{2}\left(\right.$ bipy $\left.\left.^{-}\right)\right]^{2+}$, and $\left.\left[\mathrm{Ir}^{\mathrm{II}} \text { (bipy)(bipy }{ }^{-}\right)_{2}\right]^{+}$apparently contain $\mathrm{MV}$ ligands with trapped valencies. ${ }^{41.42}$ Accordingly, IT bands of these complexes were detected in the near IR. For example, the latter complex displays its IT band at $\lambda_{\max }=2600 \mathrm{~nm}$. However, the CT nature of these IT transitions has not yet been confirmed experimentally. The energy of a real bipy ${ }^{-}$to bipy LLCT band should depend on the polarity of the solvent. Such measurements or other additional evidence in favor of the CT character of these IT bands have not yet been reported.

Quite recently, a new family of LBMV complexes has been discovered. These compounds contain two coplanar porphyrin rings which are bridged by a large metal cation via coordination of the porphyrin nitrogen atoms. The central ion is a lanthanoid $\left(\mathrm{Pr}^{\mathrm{III}}, 43.44\right.$ $\left.\mathrm{Eu}^{\mathrm{III}}{ }^{43} \mathrm{Ce}^{\mathrm{IV}}{ }^{45}\right)$ or actinoid $\left(\mathrm{Th}^{\mathrm{IV}}, \mathrm{U}^{\mathrm{IV}}\right)^{46}$ metal. These LBMV complexes contain one porphyrin in its usual form and one oxidized to the $\pi$-radical cation. The extent of delocalization of the electron hole over both ligands does not seem to be clear. Although an IT band appears in the near IR it has been suggested that this transition involves little CT. ${ }^{46}$ In this context it is certainly of interest 
that such an IT band $\left(\lambda_{\max }=1300 \mathrm{~nm}\right)$ was also detected in the electronic spectrum of the oxidized special pair of two chlorophyll molecules which occurs in the reaction center of bacterial photosynthesis. ${ }^{47}$

(c) In this section LBMV complexes are discussed which definitely contain completely delocalized MV ligands. In this case IT transitions without any CT contribution occur.

A large variety of square-planar $\mathrm{d}^{8}$ complexes of $\mathrm{Ni}(\mathrm{II}), \mathrm{PJ}$ (II), and $\mathrm{Pt}$ (II) with two chelating ligands of the same stoichionetry but in formally different redox states are known ${ }^{18.49}$ :

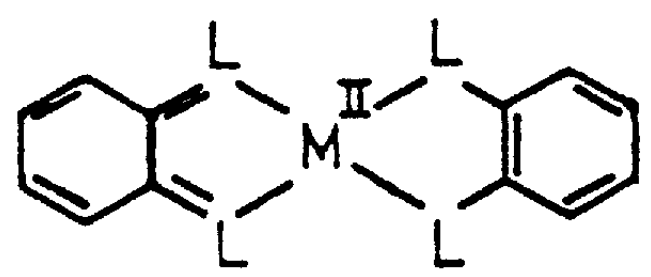

The coordinating atoms $L$ are either $O, S$ or $N(N R)$. In the case of $L=O$ the ligands are o-quinone and its deprotonated hydroquinone dianion. The redox properties of the ligands remain essentially unchanged if this ligand structure is preserved only partially ${ }^{48.49}$ :

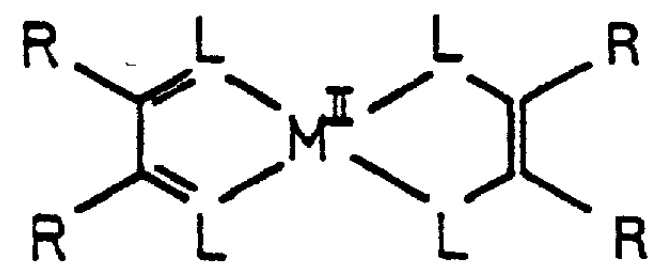

However, both ligands are completely delocalized. In a va ence bond picture the electron distribution must then be described by two equivalent resonance forms ${ }^{50}$ :

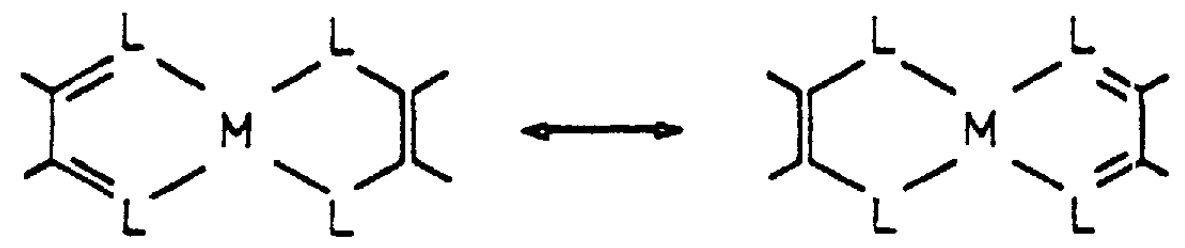


This situation is also reflected by MO considerations of these compounds. ${ }^{50-52}$ The highest occupied $\left(2 b_{1 u}\right)$ and the lowest empty $\left(3 b_{2 g}\right)$ ligand orbitals are equally delocalized over both ligands.

The largest group of complexes of this type are the dithiolenes $(\mathrm{L}=\mathrm{S}){ }^{48.49}$ All compounds are deeply colored. This color is caused by the IT band of the $2 b_{14} \rightarrow 3 b_{2 g}$ transition. Since this transition does not have any CT character the energy of the absorption maximum does not depend on the polarity of the solvent.

In many cases the delocalized $2 b_{1 u}$ and $3 b_{2 g}$ ligand orbitals are the HOMO and LUMO of the whole complex. One-electron reduction and oxidation are then ligand-based processes. ${ }^{48.49}$ In a formal sense the complexes now contain a semiquinone-type ligand in addition to the hydroquinone or quinone-related ligand. The compounds are still delocalized LBMV complexes which are characterized by a long-wavelength IT band which belongs to the $2 b_{1 u} \rightarrow 3 b_{2 g}$ transition without any CT contribution.

(d) For delocalized LBMV complexes which are discussed in the previous section (c), a redox asymmetry can be introduced by a chemical modification of one ligand. The resulting compounds are MV complexes only in a more general sense since the chemical composition of both "MV" ligands is no longer identical. The same generalization was applied to MBMV complexes ${ }^{3.29}$ (see above).

A chemical modification is possible in two ways. A slight redox asymmetry

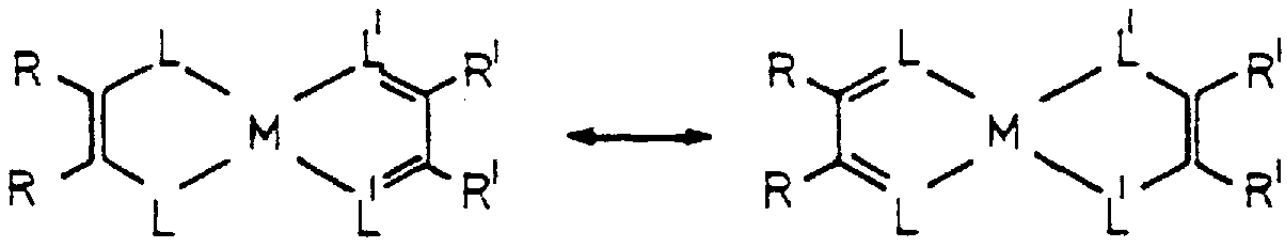

is achieved if $L=L^{\prime}$ and $R \neq R^{\prime}$. In the ground state the left resonance form prevails slightly over the right one if $R$ is more electron-withdrawing than $\mathrm{R}^{\prime}$. For the IT excited state the opposite is true. In terms of MO theory this means that the $2 b_{14}$ orbital is now slightly more localized at the ligand with $L$ and $3 b_{28}$ at the ligand with L'. The $2 \mathrm{~b}_{1 u} \rightarrow 3 \mathrm{~b}_{2 g}$ transition in ( $D_{2 h}$ symmetry) takes now place between orbitals which are largely but not any 
more exclusively delocalized. The IT transition then has a small $C T$ contribution. This assumption was experimentally verified. ${ }^{53}$

The neutral complex $\mathrm{Ni}\left[\mathrm{S}_{2} \mathrm{C}_{2}(\mathrm{CN})_{2}\right]\left[\mathrm{S}_{2} \mathrm{C}_{2} \mathrm{Ph}_{2}\right]$ would be a good example since the nitrile substituents are much more strongly electron-withdrawing than the phenyl groups. Unfortunately, this :omplex is not stable but its reduced monoanion can be taken instead since the localization of the MO's should not change upon reduction of the neutral complex:<smiles>N#CC1=C(C#N)S[N+]2(C=C(c3ccccc3)S2)S1</smiles>

Indeed, there is evidence that this resonance form prevails slightly in the ground state. The complex ion shows a small negative solvatochromism. The $2 b_{14} \rightarrow 3 b_{2 g}$ IT band undergoes a small red shift with decreasing solvent polarity.

A large redox asymmetry can be accomplished if the coordinating atoms of both ligands are different $\left(L^{\prime} \neq L^{\prime}\right)$. The protolype of such complexes contains a 1,2-ethylenedithiolate as reducing and a 1,2-diimine as oxidizing ligand:

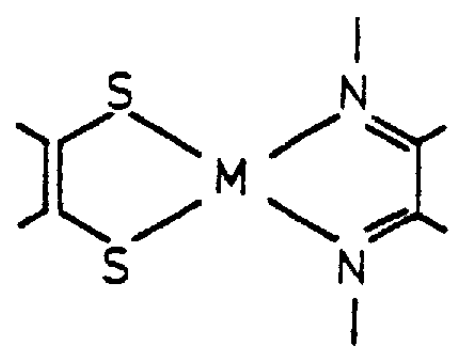

The first nickel(II) complexes of this structure were synthesized and characterized by Miller and Dance in $1973 .{ }^{5+}$ During the last decade a large number of these compounds with $\mathrm{M}=\mathrm{Ni}(\mathrm{II})$, $\mathrm{Pd}(\mathrm{II})$, and $\mathrm{Pt}$ (II) has been reported. $.^{55}-59$ The 1,2-diimines also include the classical ligands bipy and o-phen. In a few cases the 1,2-dithiolates were replaced by catecholates.

The donor orbital $2 b_{14}$ is now predominantly localized at the dithiolate while the acceptor orbital $3 b_{2 g}$ (in $D_{2 h}$ symmetry) resides 
essentially at the diimine. Consequently, the $2 b_{1 \mathrm{u}} \rightarrow 3 \mathrm{~b}_{2 \mathrm{~g}}$ transition is then a real LLCT transition. The energy of the LLCT bands is a sensitive function of the solvent polarity and the compounds exhibit a large negative solvatochromism. The solutions of less polar solvents such as $\mathrm{CH}_{2} \mathrm{Cl}_{2}$ are frequently blue while solutions of rather polar solvents such as $\mathrm{CH}_{3} \mathrm{CN}$ are often red. The $2 b_{14}$ and $3 b_{2 g}$ orbitals are apparently quite pure ligand orbitals with little metal character. This is indicated by the observation that the energy of the LLCT bands depends only slightly on the metal ( $\mathrm{Ni}(\mathrm{II}), \mathrm{Pd}(\mathrm{II})$, and $\mathrm{Pt}(\mathrm{II})) .{ }^{56} \mathrm{~A}$ detailed description of the ligand-ligand interaction supported by $\mathrm{MO}$ calculations has been reported recently. ${ }^{58.60}$

The mutual orientation of donor and acceptor ligands is certainly aiso important. The electronic coupling of both ligands seems to be very strong in square-planar complexes. In tetrahedral complexes with an orthogonal orientation of the ligands, the interaction may be absent. An intermediate situation could apply to the complexes $\left[\mathrm{Zn}^{\mathrm{ll}}\right.$ (diimine)(toluenedithiolate) $]$ with diimine = bipy and o-phen. ${ }^{61}$ Although their geometry is not known, four-coordinate $\mathrm{Zn}$ (II) complexes generally prefer tetrahedral structures. The LLCT bands of these $\mathrm{Zn}$ complexes are much less intense ${ }^{61}$ compared to those of corresponding square-planar complexes. ${ }^{53}$ This is a good indication that the LBMV complexes of zink are indeed distorted towards a tetrahedral structure and the ligand-ligand interaction deviates from that of analogous $\mathrm{Ni}(\mathrm{II})$ or $\mathrm{Pt}(\mathrm{II})$ compounds.

The complexes [Cu ${ }^{\mathrm{Il}}$ (diimine)(3,5-di-tert.-butylcatecholate)] with diimine $=$ bipy and o-phen also show long-wavelength absorptions which were assigned to LLCT transitions. ${ }^{62,63}$ For the bipy complex this band appears at $\lambda_{\max }=530 \mathrm{~nm}$ (in DMSO) while the corresponding square-planar $\mathrm{Pt}$ (II) complex displays this absorption at $\lambda_{\max }=570 \mathrm{~nm}$ (in DMF). ${ }^{57}$ Again, this difference could be caused by structural differences. These copper complexes may deviate from a planar structure.

Finally, octahedral LBMV complexes which are characterized by LLCT bands are also known. In this case the MV chelate ligands cannot be arranged in a plane, too. In the electronic spectrum of $\left[C d^{\text {II }}\left(\text { o-phen)(toluenedithiolate) }{ }_{2}\right]^{2-}\right.$ a shoulder at $400 \mathrm{~nm}$ (in $\mathrm{CH}_{3} \mathrm{CN}$ ) was assigned to a LLCT transition. ${ }^{62.63}$ LLCT absorptions were also identified in the spectra of $\left[R u^{I I} \text { (bipy) }\right)_{2}$ (catecholate) $]$ and 
$\left[\mathrm{Ru}^{\mathrm{II}} \text { (bipy)(catecholate) }{ }_{2}\right]^{2-}$ complexes. ${ }^{64,65}$ The spectra of these compounds are rather complicated since other bands such as MLCT absorptions appear in the same wavelength region as the catecholate to bipy LLCT bands. Interestingly, these LLCT bandis are also present in the spectra of complexes in which the catecholate ligand is oxidized to the semiquinone. The donor ability is essentially unchanged by this oxidation.

\section{EXCITED STATE PROCESSES INVOLVING LLCT STATES}

In all cases which have been discussed so far LLCT excited states are generated directly by light absorption into LLCT bands. Generally, the LLCT excited complexes return to their ground states by radiationless deactivation. However, in some cases the generation and deactivation of LLCT excited states takes place by other processes.

The population of a LLCT state can also occur from excited states of a different origin. For example, the complex $\left\{\operatorname{Re}^{I}\right.$ (bipy) $(\mathrm{CO})_{3}$ (py-PTZ) $]^{+}$contains a coordinated pyridine (py) which is linked at its 4 position to the reducing phenothiaine (PTZ) molecule via a methylene group. ${ }^{66}$ A PTZ to bipy LL.CT absorption was not observed. The electronic coupling between PTZ and bipy is probably too weak due to the intervening $\mathrm{CH}_{2}$ group. Light absorption by a MLCT band leads to the excited s:ate $\left[\mathrm{Re}^{\mathrm{II}}\left(\text { bipy }^{-}\right)(\mathrm{CO})_{3} \text { (py-PTZ) }\right]^{+}$which undergoes a rapid excited state electron transfer from PTZ to the oxidized Re center. The result of this excited state electron transfer is a LLCT excited state with the electron distribution $\left[\operatorname{Re}^{\mathrm{I}}\left(\text { bipy }^{-}\right)(\mathrm{CO})_{3}\left(\mathrm{py}-\mathrm{PTZ}^{+}\right)\right]^{+}$. It reverts to the ground state with $k=4 \times 10^{8} \mathrm{~s}^{-1}$.

Occasionally, the deactivation of LLCT excited states does not occur by radiationless deactivation but also by emission or photochemical reaction. The complex [ $\mathrm{Pt}^{\mathrm{II}}$ (bipy)(toluenedithiolate)] is excited to a LLCT state directly by light absorption. ${ }^{55}$ At $77 \mathrm{~K}$ the LLCT state returns to the ground state by emission. At rcom temperature in an ethanol solution this luminescence is quencined by a competing radiationless deactivation. However, in solutions of $\mathrm{CHCl}_{3}$ the LLCT excited state transfers an electron to the sol- 
vent. This leads to an irreversible photooxidation of the complex. Low-temperature $(77 \mathrm{~K})$ emission from LLCT excited states was also observed for the complexes $\mathrm{M}^{\mathrm{II}}$ (diimine)(RS) $)_{2}$ with $\mathrm{M}=\mathrm{Zn}$ and $C d$, diimine $=$ bipy and o-phen, and $R=$ aryl groups ${ }^{13,14}$ (see above).

Complexes of the form $\left[\operatorname{Re}^{1} \text { (bipy)(CO) }{ }_{3}(\mathrm{DMABN})\right]^{+}$and $\left[\mathrm{Os}^{11}\left(\text { bipy }_{2}(\mathrm{CO})(\mathrm{DMABN})\right]^{2+}\right.$ with the donor ligand $\mathrm{DMABN}=$ 4-(N,N-dimethylamino)benzonitrile possess DMABN to bipy LLCT excited states which are populated by electron transfer from a MLCT excited state and deactivated by emission. ${ }^{67}$

\section{INTRALIGAND CHARGE TRANSFER (ILCT) AND OUTER-SPHERE LIGAND TO LIGAND CHARGE TRANSFER}

A ligand itself may consist of a reducing and an oxidizing part. The spectrum of the metal complex should then show a low-energy ILCT band involving a CT transition from the donor to the acceptor site of the same ligand. Such a long-wavelength ILCT band was detected in the absorption spectrum of a $\mathrm{Ni}$ (II) complex with a quadridentate ligand ${ }^{68}$ :

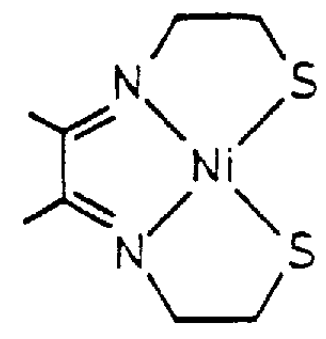

The donor site is the reducing thiolate moiety while the diimine is the accepting part of the ligand. The solvent dependence of the ILCT band causes a large negative solvatochromism of this com. pound. The donor-acceptor interaction within the complex is clearly of the inner-sphere type since the nickel ion mediates the electronic coupling. The free ligand apparently does not exist. It might be expected to show also a CT absorption. This, however, would 
belong to an outer-sphere CT transition since donor and acceptor sites are separated by electronically insulating methylene groups.

Quite recently, such ILCT bands were also detected in the absorption spectra of related $\mathrm{Zn}$ (II) and $\mathrm{Ni}$ (II) complexes ( $\mathrm{L}:=\mathrm{O}$ or $\mathrm{S})^{69}$ :

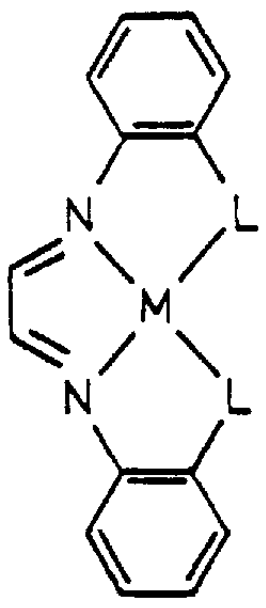

A LLCT transition cannot only occur by an inner-sphere interaction within a complex; in addition, it may take place as an outersphere process if the donor and acceptor ligand are located at different complexes. The necessary close approach is facilitatecl by electrostatic attraction within ion pairs of both complexes. Intense long-wavelength absorption bands at $\lambda_{\max } \sim 830 \mathrm{~nm}$ appear in the spectra of $\left[\mathrm{Ni}^{\mathrm{II}}(\mathrm{tim})\right]^{2+}\left[\mathrm{M}^{\mathrm{II}}(\mathrm{mnt})_{2}\right]^{2-}$ with $\mathrm{M}=\mathrm{Ni}$, Pd and $\mathrm{Pi}^{70}$ :

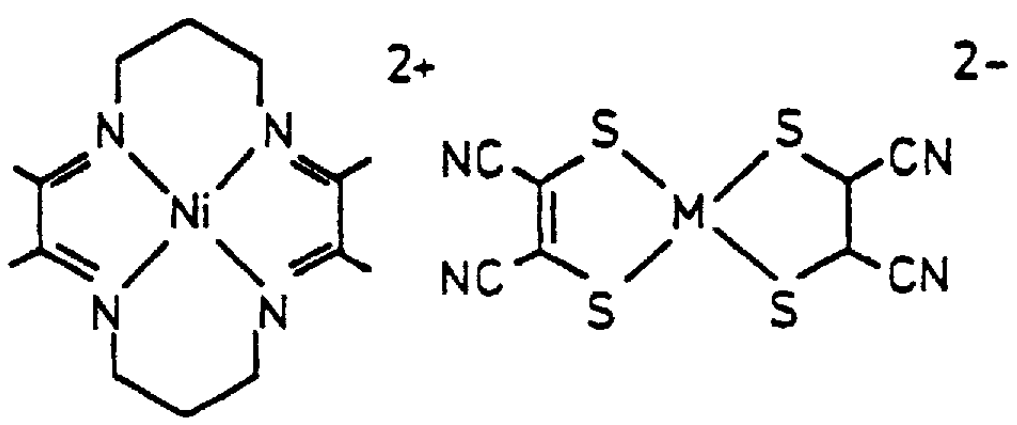

There is good evidence that this band belongs to an outer-sphere LLCT transition from the dithiolate ligand of the complex anion to the diimine moiety of the macrocyclic complex cation. 


\section{CONCLUSION}

LLCT seems to be a rather general type of electronic transition of metal complexes which contains a donor and acceptor ligand. There is no doubt that many more examples will be discovered in the future, including ligand-based mixed-valence complexes.

\section{References}

1. A. B. P. Lever, Inorganic Electronic Spectroscopy (Elsevier. Amsterdam, 1984).

2. G. L. Geoffry and M. S. Wrighton, Organometallic Photochemistn' (Academic Press, New York, 1979).

3. A. Vogler, A. H. Osman and H. Kunkely, Coord. Chem. Rev. 64, 159 (1985).

4. A. Vogler and H. Kunkely, Z. Naturforsch. 44b, 132 (1989).

5. A. Vogler and H. Kunkely, J. Organomet. Chem. 355, 1 (1988).

6. H. Kunkely, G. Stochel and A. Vogler, Z. Naturforsch. 44b, 145 (1989).

7. E. M. Kosower, Progress in Physical Organic Chemistry, eds. S. G. Cohen, A. Streitwieser and R. W. Taft (Interscience. New York. 1965), Vol. 3, p. 81.

8. G. E. Coates and S. 1. E. Green. J. Chem. Soc. 3340 (1962).

9. A. Paukner, H. Kunkely and A. Vogler, Photochemistry and Photophysics of Coordination Compounds, eds H. Yersin and A. Vogler (Springer-Verlag. Berlin. 1987), p. 205.

10. H. Rau and K. H. Thiele, Z. Anorg. Allg. Chem. 335, 253 (1967).

11. J. G. Noltes and J. Boersma, J. Organomet. Chem. 9. 1 (1967).

12. J. G. Noltes and J. W. G. van den Hurk. J. Organomet. Chem. 3. 222 (1965).

13. K. A. Turesdell and G. A. Crosby, J. Am. Chem. Soc. 107, 1787 (1985).

14. G. A. Crosby, R. G. Highland and K. A. Truesdell, Coord. Chem. Rev . 64, 41 (1985).

15. P. M. Gidney. R. D. Gillard and B. T. Heaton. J. Chem. Soc., Dalton Trans. 132 (1973).

16. N. Chaudhury and R. J. Puddephatt, J. Organomet. Chem. 84. 105 (1975).

17. D. L. Webb and L. A. Rossiello, Inorg. Chem. 10, 2213 (1971).

18. L. K. Hanson, W. A. Eaton, S. G. Sligar, 1. C. Gunsalus, M. Gouterman and C. R. Connell, J. Am Chem. Soc. 98, 2672 (1976).

19. M. Nappa and J. S. Valentine, J. Am. Chem. Soc. 100, 5075 (1978).

20. J. V. Nardo, M. Sono and J. H. Dawson, Inorg. Chim. Acta 151. 173 (1988).

21. N. M. Kostic and R. F. Fenske, Organometallics 1. 489 (1982).

22. N. S. Hush, Progr. Inorg. Chem. 8, 391 (1967).

23. M. B. Robin and P. Day, Adv. Inorg. Chem. Radiochem. 10, 247 (1967).

24. H. Taube, Ann. N.Y. Acad. Sci. 313, 483 (1978).

25. T. J. Meyer, Acc. Chem. Res. 11, 94 (1978).

26. T. J. Meyer, Ann. N.Y. Acad. Sci. 313, 496 (1978).

27. D. Brown (ed.), Mixed-Valence Compounds (Reidel, Dordrecht, 1980).

28. C. Creutz. Progr. Inorg. Chem. 30, 1 (1980).

29. A. Vogler, A. H. Osman and H. Kunkely, Inorg. Chem. 26. 2337 (1987).

30. F. Wöhler, Ann. Chem. Pharm. 51. 145 (1844). 
31. H. Staab and W. Rebafka, Chem. Ber. 110, 3333 (1977).

32. G. N. Schrauzer. Adv. Organomet. Chem. 2. 1 (1964).

33. E. Weiss and W. Hübel. J. Inorg. Nucl. Chem. 11. 42 (1959).

34. C. G. Pierpont and R. M. Buchanan, Coord. Chem. Rev. 38. 45 (1981).

35. For recent references see: G. A. Fox and C. G. Pierpont. J. Chem. Soc. Chem. Commun. 806 (1988)

36. C. G. Pierpont and R. M. Buchanan. J. Am. Chem. Soc. 97, 4912 (1975).

37. M. Zehnder and $H$. Löliger. Helv. Chim. Acta 63, 75+ (1980).

38. R. M. Buchanan and C. G. Pierpont, J. Am. Chem. Soc. 102. 4951 (1981)).

39. M. W. Lynch. M. Valentine and D. N. Hendrickson, J. Am. Chem. Soc. 104. 6982 (1982).

40. C. Creutz, Comments Inorg. Chem. 1. 293 (1982).

41. G. A. Heath. L. J. Yellowlees and P. S. Braterman. Chem. Phys. Lett. 92. 646 (1982).

42. V. T. Coombe. G. A. Heath, A. J. MacKenzie and L. J. Yellowlees. Inorg. Chem. 23, 3423 (1984).

43. J. W. Buchler and M. Knoff. Optical Properties and Structures of Tetrapyrrcles. eds. G. Blauer and H. Sund (deGruyter. Berlin. 1985). p. 91.

44. J. W. Buchler, M. Kihn-Botulinski and B. Scharbert. Z. Naturforsch. \$3b. 1371 (1988).

45. J. W. Buchler, K. Elsässer. M. Kihn-Botulinski and B. Scharbert, Angew. Chem.. Int. Ed. Engl. 25, 286 (1986).

46. G. S. Girolami, S. N. Milam and K.-S. Suslick. J. Am: Chem. Soc. 110. 2011 (1988).

47. M. S. Daris, A. Forman. L. K. Hanson. J. P. Thornber and J. Fajer. J. Phys. Chem. 83, 3325 (1979).

48. J. A. McCleverty, Progr. Inorg. Chem. 10, 49 (1968).

49. R. P. Burns and C. A. McAuliffe, Adv. Inorg. Chem. Radiochem. 22. 303 (1979).

50. G. N. Schrauzer, Acc. Chem. Res. 2, 72 (1969).

51. G. N. Schrauzer and V. P. Mayweg. J. Am. Chem. Soc. 87. 3585 (1965).

52. Z. S. Hermann, R. F. Kirchner, G. H. Loew, U. T. Müller-Westerhoff. A. Nazzal and M. C. Zerner, Inorg. Chem. 21. 46 (1982).

53. A. Vogler and H. Kunkely. Angew. Chem., Int. Ed. Engl. 21. 77 (1982).

54. T. R. Miller and I. G. Dance, J. Am. Chem. Soc. 95.6970 (1973).

55. A. Vogler and H. Kunkely. J. Am. Chem. Soc. 103, 1559 (1981).

56. A. Vogler, H. Kunkely, J. Hlavatsch and A. Merz. Inorg. Chem. 23, 506 (1984).

57. L. Kumar, K. H. Puthraya and T. S. Srivastava. Inorg. Chim. Acta 86. 173 (1984).

58. R. Benedix, D. Pitsch, K. Schöne and K. Hennig, Z. Anorg. Allg. Chem. 342, 102 (1986).

59. G.-E. Matsubayashi, M. Hirao and T. Tanaka, Inorg. Chim. Acta 144, 2.17 (1988).

60. R. Benedix and H. Hennig. Inorg. Chim. Acta 141. 21 (1988).

61. V. J. Koester, Chem. Phys. Lett. 32. 575 (1975).

62. A. Vogler and J. Hlavatsch, unpublished results.

63. J. Hlavatsch. Ph. D. Thesis, University of Regensburg, 1985.

64. M. Haga. E. S. Dodsworth and A. B. P. Lever, Inorg. Chem. 25.447 (1986).

65. A. B. P. Lever, P. R. Auburn, E. S. Dodsworth. M. Haga, W. Liu. M. Mel nik and W. A. Nevin, J. Am. Chem. Soc. 110. 8076 (1988). 
66. T. D. Westmoreland. K. S. Schanze. P. E. Neveux. E. Danielson. B. P. Sullivan. P. Chen and T. J. Mever. Inorg. Chem. 24. 2596 (1985).

67. K. S. Schanze. T. A. Perkins. T. L. Netzel and D. B. Pourreau. Abstracts of the 196th ACS National Meeting. Los Angeles. Sept. 25-30. 1988. DIC 180.

68. A. Vogler and H. Kunkely. Inorg. Chim. Acta 54. L273 (1981).

69. R. Benedix. F. Dietz and H. Hennig. Inorg. Chim. Acta 147. 179 (1988).

70. A. Vogler and H. Kunkely. J. Chem. Soc. Chem. Commun. 1616 (1986). 